\title{
Optimal Seismic Network Density for Earthquake Early Warning: A Case Study from California
}

\section{by H. Serdar Kuyuk and Richard M. Allen}

\section{INTRODUCTION}

Earthquake Early Warning Systems (EEWS) rapidly detect the initiation of earthquakes and issue warning alerts of possible forthcoming ground shaking. Currently, public warning systems exist in Japan and Mexico, and the development of other EEWS are ongoing in many other regions of the world including the U.S. West Coast (Allen et al., 2009). Probing the way business and the public actively use early warning information is a crucial factor in early warning system design (Aktas et al., 2010; Kuyuk, 2010; Kuyuk et al., 2008; Nakamura, 1988). During the 2011 M 9 Tohoku-oki, Japan, earthquake, an earthquake warning was successfully issued although the magnitude was underestimated (Hoshiba et al., 2011). To determine the usefulness of the alerts, the Japan Meteorological Agency (JMA) conducted a public survey (JMA, 2012). Results from the $\sim 2000$ people who answered the survey indicated that most people want two main pieces of information from an EEW message: the time when strong shaking is expected to begin at their location and the estimated shaking intensity. The survey also showed that although the JMA warnings provide additional information about the earthquake location, magnitude, and depth, people are less interested in this information and more interested in the potential impending dangers the large earthquake might cause at their location.

Many factors contribute to the time between the issued earthquake warning and the subsequent ground shaking at a given location. In this paper, we refer to this period as the warning time. The warning-time duration is dictated by many factors, of which the most important are the proximity of stations to the earthquake epicenter, data telemetry speed, data processing time, and the time needed to disseminate the warning. Once an alert is generated, the amount of warning time is a function of the distance of the user from the epicenter, in which more distant locations receive longer warning time.

One of the challenges with EEWS is minimizing the blind zone, that is, the region around the epicenter where no warning is possible because the strong shaking has already occurred by the time the alert is generated. Some factors that influence the radius of the blind-zone area are simply out of our control. For example, we cannot dictate exactly where earthquakes occur and how deep an earthquake hypocenter is. However, there are many things we can do to reduce the size of the blind zone.
For example, (a) using the most advanced telecommunication technologies that can potentially decrease the current telemetry delay; (b) decreasing data packet size to less than $0.5 \mathrm{~s}$; (c) improving event detection and alert-filtering algorithms; and (d) well-developed seismic networks with improved station density deployed across seismogenic zones. The degree to which these improvements can be made depend on how close the seismic stations are to the earthquake epicenter, the distance between the warning site and the earthquake epicenter, the depth of earthquake, the density of the seismic network, the telemetry delay, and the time needed for decision making in regard to the type of warning that should be issued. The blind zone as defined in this paper is the radius from the epicenter to the distance traveled by the seismic $S$ wave at the time the alert is issued. It is a minimum value, as for any practical use, the blind zone will be larger depending on the time required for a specific action to be taken once the alert is received.

One of the most advanced EEWS was developed by the National Research Institute for Earth Science and Disaster Prevention (NIED) and the JMA in Japan. This advanced system includes 1089 stations from two separate networks: Hi-net and JMA with an average of $18.7 \mathrm{~km}$ station spacing. In California, the California Integrated Seismic Network (CISN), which consists of multiple, complementary seismic networks $(\sim 2900$ stations, http://www.cisn.org/; last accessed May 2013) operate seismometers and accelerometers; 587 of them, located at 377 sites (Fig. 1), provide real-time waveforms to CISN/ShakeAlert EEWS (Boese et al., 2013). Interstation distances between stations in the California network vary significantly from region to region ranging from 2 to $100 \mathrm{~km}$. For example, the interstation distance is less than $5 \mathrm{~km}$ in densely populated regions such as the San Francisco Bay and Los Angeles regions; however, in northeastern California the interstation distances tend to be much larger at a spacing of $\sim 70 \mathrm{~km}$. This nonuniformity in seismic-station spacing throughout California differs drastically from the station spacing in the Japan network, which has made significant strides in this area by deploying a dense array of seismic stations, leaving few areas without service.

The incentive to upgrade and densify seismic networks is often driven by devastating large earthquakes, which get the attention of not only the public, but also policy makers. For example, the USGS/Caltech Southern California Seismic Network (CI) in southern California were upgraded after the 
1994 Northridge earthquake, and the Hi-net network in Japan was upgraded after the 1995 Kobe earthquake. These upgrades have improved our ability to issue more accurate EEWS, as evidenced by the earthquake warning issued by JMA for the 2011 Tohoku earthquake (JMA, 2012).

The question we address in this paper is what changes should be made to the CISN to improve EEWS in California. Our overall goal is to explore how to design an ideal station distribution that will maximize the warning time, in addition to identifying target areas where it would be beneficial to make modifications to the spatial distribution of stations in order to improve EEWS performance. This study is particularly timely given that California enacted a law to implement a public EEWS in September 2013.

\section{METHODOLOGY}

\section{Exploring How to Increase Warning Times}

A decade ago, many scientists doubted that the magnitude and location of an earthquake could be calculated using only $P$ wave data (Kilb and Gomberg, 1999), and many were skeptical if EEWS could be successfully implemented in California. However, in 2007 an EEWS was designed by the CISN ShakeAlert project, which is now automatically issuing early warning alerts to more than 50 institutes and scientists. In general, the basic concept behind an EEWS is to estimate an earthquake's location and magnitude from the frequency and amplitude from the first few seconds of the $P$ wave recorded at stations closest to the earthquake. Without EEW, there was no urgency to compute these parameters quickly, whereas there is a demand now because it can provide key information allowing rapid response through automatic control of devices and facilities.

Ground-motion prediction equations are being used to predict the spatial distribution of peak ground shaking at a given location given the magnitude. In general, the quality of the hazard prediction increases in accuracy as the earthquake source is more confidently known; this increases as more data becomes available from more stations. In terms of EEWS, this increased accuracy results in a trade-off; waiting for more data to come on line will decrease the warning time, whereas warnings issued with minimal delay can have large uncertainties. In this paper, we explore how to obtain the ideal balance between increasing the speed of issuing a warning without compromising the uncertainty.

The warning time $t_{\mathrm{W}}$ can be defined as

$t_{\mathrm{W}}=\Delta t-t_{\mathrm{D}}$

in which $\Delta t$ is the theoretical time between the $P$-wave detection at the closest sensor(s) in the epicentral region and the arrival of high-amplitude $S$ or surface waves at the site where the warning is to be issued. The parameter $t_{\mathrm{D}}$ is the system delay, which comprises delays from data packetization, telemetry latency, and the processing/decision time for an EEW algorithm to release an earthquake alert. For the purpose of this paper, we use theoretical travel times of $P$ and $S$ waves using a standard 1D velocity model for California (Hauksson and Shearer, 1995).

We calculate theoretical warning times based on two quantities: (1) the time it takes for the earthquake $P$ wave to arrive at four stations, and (2) an estimated processing time (e.g., data telemetry speed, data processing, and time needed to disseminate the warning) that we set at a fixed value of four seconds (Allen et al., 2009). This choice of four seconds is based on the current processing performance of Earthquake Alarm Systems (ElarmS) in California, which is one of the algorithms of the CISN ShakeAlert EEWS (Brown et al., 2011). ElarmS requires a minimum of four stations to trigger on a $P$ wave before an alert is issued. The requirement of four stations, rather than a smaller number, is to reduce the number of false alerts to an acceptable level. Current real-time processing by ElarmS also shows that the average delay between the arrival time of the $P$ wave at the fourth station and the alert being issued is four seconds (Kuyuk et al., 2013).

\section{The Blind Zone: Quantifying Where an Earthquake Alert is Possible}

The blind zone is defined as the region that does not receive an earthquake alert before the $S$-wave arrival. The size of the blind zone depends on the time needed to detect the event, that is, wave propagation to the closest seismic stations, and the system delay time that includes transmission and processing delays (assumed to be $4 \mathrm{~s}$ in this paper). The blind zone can be defined in terms of a radius around the earthquake epicenter, for which this radius can be quantitatively formulated as:

$b=\sqrt{\left(t_{P}^{\text {station }}+t_{\mathrm{D}}\right)^{2} V_{S}^{2}-D^{2}}$,

in which $t_{P}^{\text {station }}$ is the time for the $P$ wave to be detected by four stations, $V_{S}$ is the $S$-wave velocity and $D$ is the depth of earthquake. The blind-zone radius depends on how close the seismic stations are to the earthquake epicenter, and the total system latency after the fourth station has detected a $P$ wave. Another factor that affects blind-zone size is the depth of earthquake. The blind-zone radius decreases for deeper earthquakes, as there is more time between the $P$ - and $S$-wave arrivals at the surface, which, in turn allows more time to issue a successful warning. The preferred scenario is to minimize the number of people and key infrastructure within the blind zone. For the more remote earthquakes, such as earthquakes offshore or in unpopulated regions, larger blind zones can be tolerated.

\section{RESULTS}

We designed 121 theoretical simulations to help us quantitatively test the sensitivity of blind zone to network density and algorithm performance (Fig. 2). These calculations are performed for earthquakes distributed throughout one quarter of a network cell unit, which, because of symmetry, sufficiently covers all possible spatial distributions. For all the possible earthquake locations, we track the blind-zone radius (Fig. 3). 


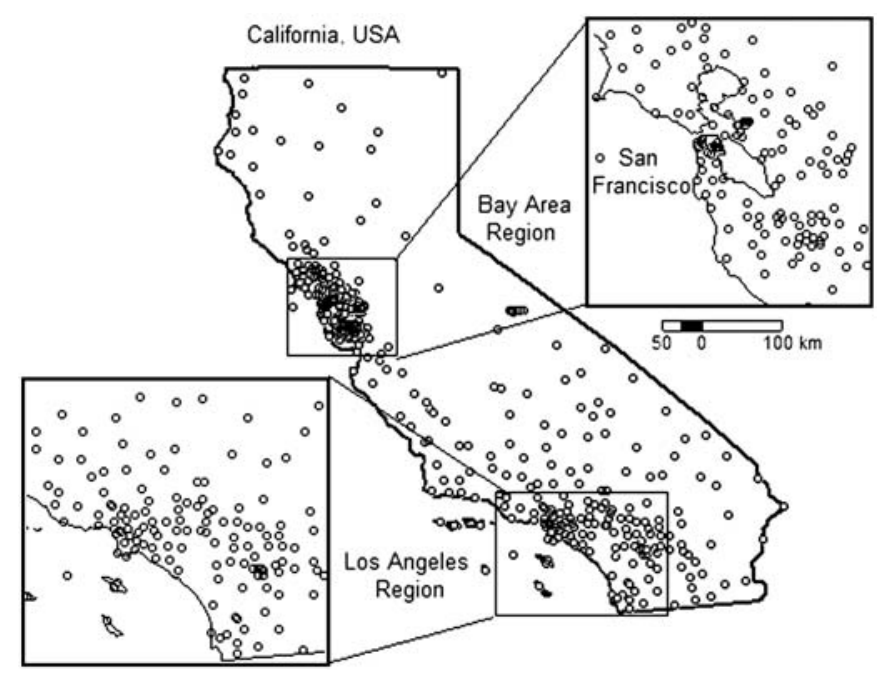

A Figure 1. Station distribution of CISN/EEWS (377 locations) throughout California, U.S.A. CISN networks are described in Table 1.

For these station/earthquake configurations, the smallest blindzone radius is $21.4 \mathrm{~km}$ and corresponds to an earthquake in the middle of the unit cell at which the $P$ wave will simultaneously arrive at the four closest stations. The largest radius produced by our models is $29.4 \mathrm{~km}$, and the average blind-zone radius is $25.5 \mathrm{~km}$.

We next estimate how the average blind-zone radius changes with varying interstation distances by examining interstation distances from 1 to $100 \mathrm{~km}$ (Fig. 4). In our calculations, we first model typical California earthquakes, which, on average, have a relatively shallow depth of $8 \mathrm{~km}$. We find that by increasing the station density 10 times (interstation distances from 100 to $31 \mathrm{~km}$ ), the radius of the blind zone decreases by $57 \%$ from 73 to $32 \mathrm{~km}$. Increasing mesh density an additional 10 times (interstation distances from 31 to $10 \mathrm{~km}$ ), the blindzone radius drops by another $37 \%$ from 32 to $20 \mathrm{~km}$. Increasing the station density by another factor of 10 (interstation distances from 10 to $3 \mathrm{~km}$ ) reduces the radius by only $15 \%$

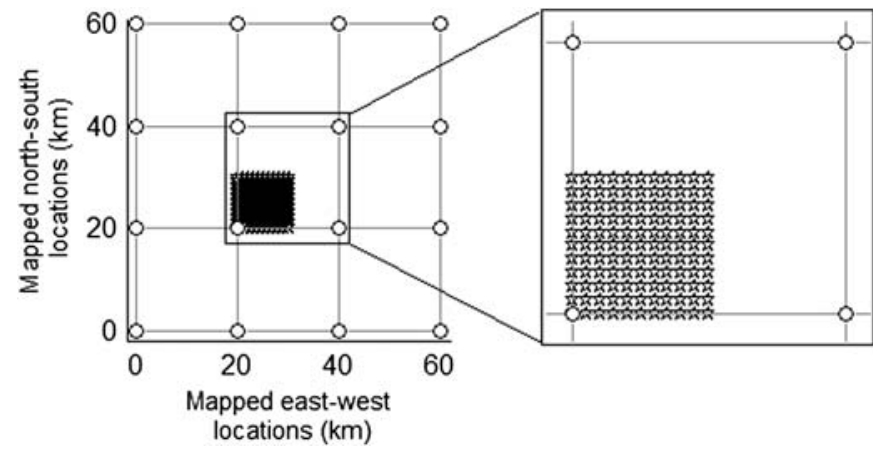

- Figure 2. Spatial schematic of warning-time simulations. A uniformly distributed network with $20 \mathrm{~km}$ station spacing (black nodes) and locations of 121 earthquake hypocenters (black stars) that are uniformly distributed on a $1 \mathrm{~km}$ grid.
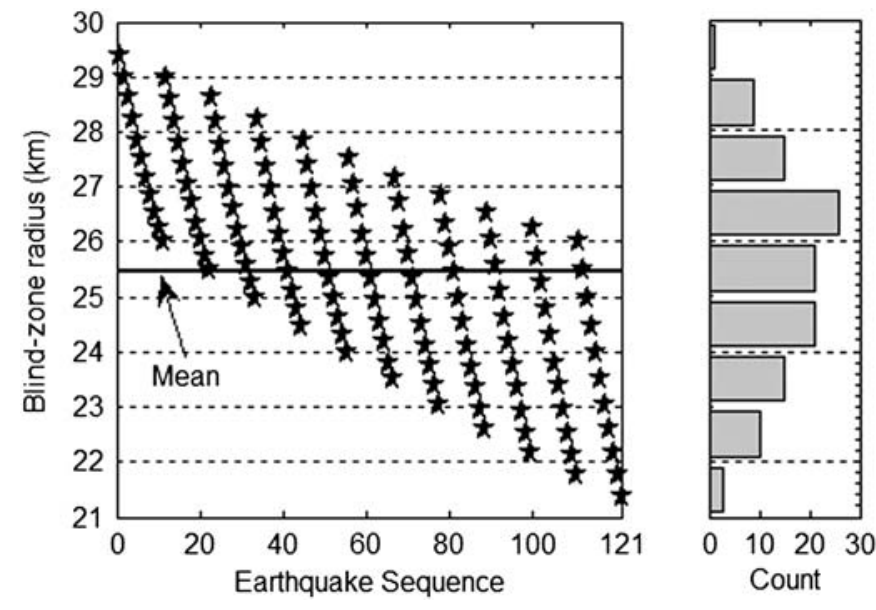

A Figure 3. Blind-zone radius for all earthquake scenarios corresponding to the spatial distribution in Figure 1. In these calculations, the interstation distance is $20 \mathrm{~km}$, the earthquakes are at $8 \mathrm{~km}$ depth, $P$-wave arrivals are required at four stations, and the assumed system delay is $4 \mathrm{~s}$.

from 20 to $17 \mathrm{~km}$. We can also compute these estimates for the spatial extent of the blind-zone area. A decrease of 57\%, $37 \%$, and $15 \%$ in blind-zone radius corresponds to an $80 \%$, $60 \%$, and $28 \%$ drop, respectively, in total blind-zone area. These results show that the relationship between station density and the blind-zone radius is not linear. Instead, there is a

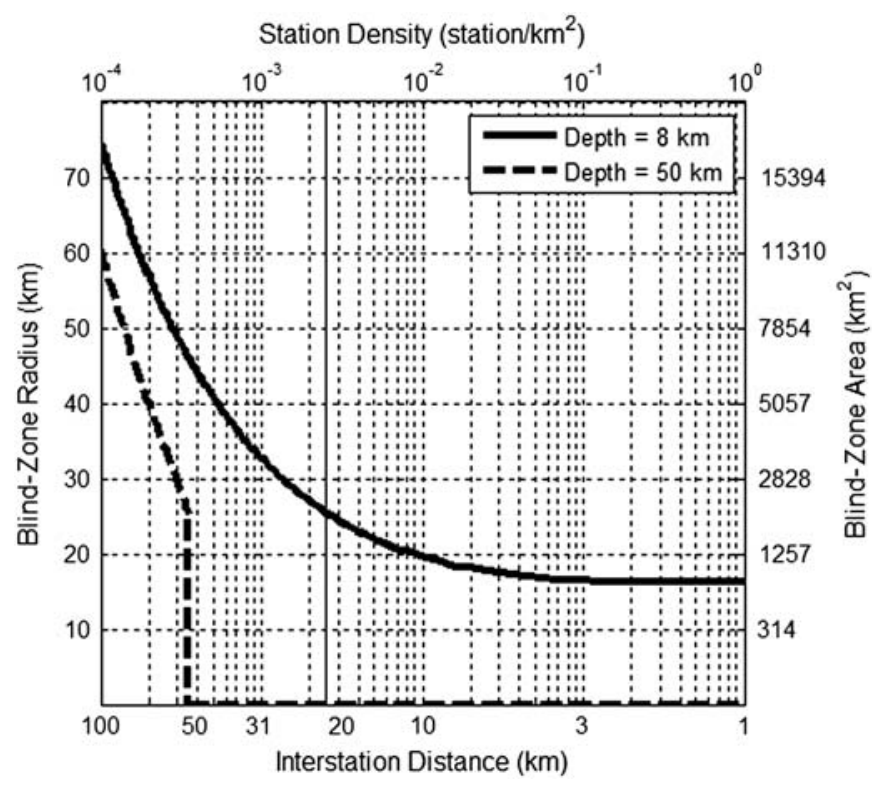

A Figure 4. Relationship between network density (or equivalent interstation distance) and blind-zone radius (or equivalent area) computed for earthquakes of different depths. The smaller $8 \mathrm{~km}$ depth (solid line) is consistent with the average depth of earthquakes in California and the larger $50 \mathrm{~km}$ depth (dash line) is consistent with what might be expected beneath the onshore regions of the Pacific Northwest from a subduction-zone earthquake. 


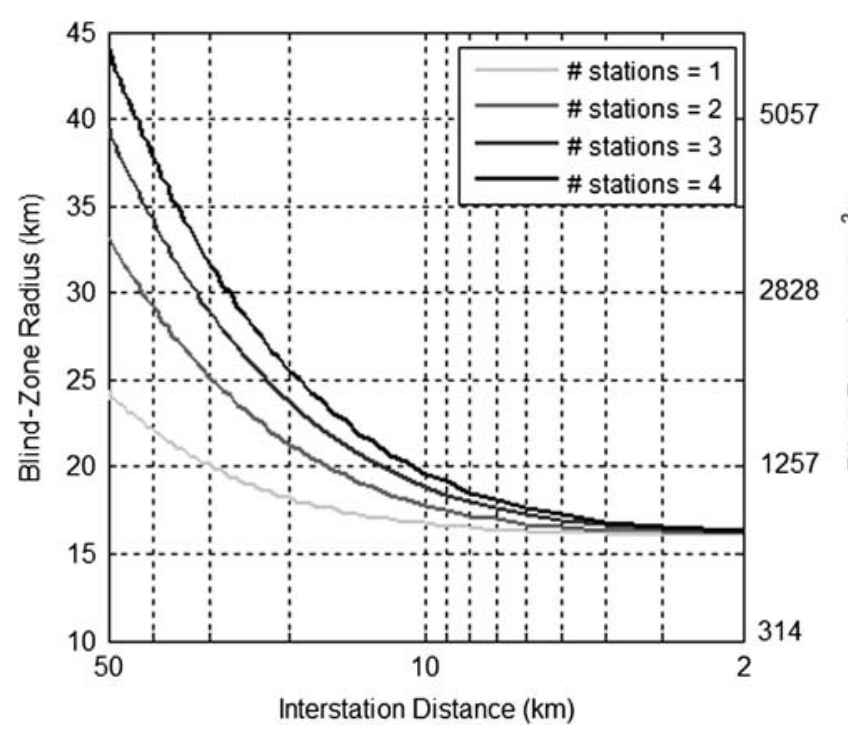

$\Delta$ Figure 5. Relationship between the interstation distance and the average blind zone with respect to the number of stations required to identify a $P$-wave arrival in the alert algorithm.

large attenuation (reduction in area) when the interstation distance is decreased from 100 down to 31 or $10 \mathrm{~km}$, but is only a small change as station density is decreased to $3 \mathrm{~km}$. As expected, the radius decreases for smaller interstation distances, but importantly we find that for shallow earthquakes the blindzone radius asymptotes toward a constant value when the interstation distance falls below a threshold value. For deeper earthquakes, which we represent by a $50 \mathrm{~km}$ depth, a sparse station distribution is adequate, the decline in the radius and area of the blind zone is steeper (Fig. 4), and we find there is no blind zone if the interstation distance is less than $52 \mathrm{~km}$.

If we decrease the number of $P$-wave station detections needed to issue an alert, the size of the blind zone also decreases (Fig. 5), but this comes at a cost, as there is more uncertainty in the information. If the number of stations required to issue an alert is reduced, then the reduction in the size of the blind zone is large when the network station spacing is large. However, for a dense seismic network, for example, the San Francisco Bay area and the Los Angles regions (see Fig. 1), the reduction in the size of the blind zone is small. Algorithms requiring fewer stations to issue an alert are, therefore, most desirable in regions with sparse networks, such as northeast California. For example, by decreasing the alert criteria from four station detections to two, the blind zone will decrease by almost a factor of two, from 44 to $24 \mathrm{~km}$ for much of California where the interstation distance is $50 \mathrm{~km}$. However, the reduction in blind-zone radius is only about $3 \mathrm{~km}$, from 20 to $17 \mathrm{~km}$, for shallower earthquakes in the San Francisco Bay area due to the denser instrumentation.

We next study how the warning time varies at locations various distances from the earthquake epicenter. In addition to our standard parameters, we assume an earthquake depth of $8 \mathrm{~km}$ and derive theoretical warning times at locations 16 , $25,50,75$, and $100 \mathrm{~km}$ from the earthquake epicenter as a

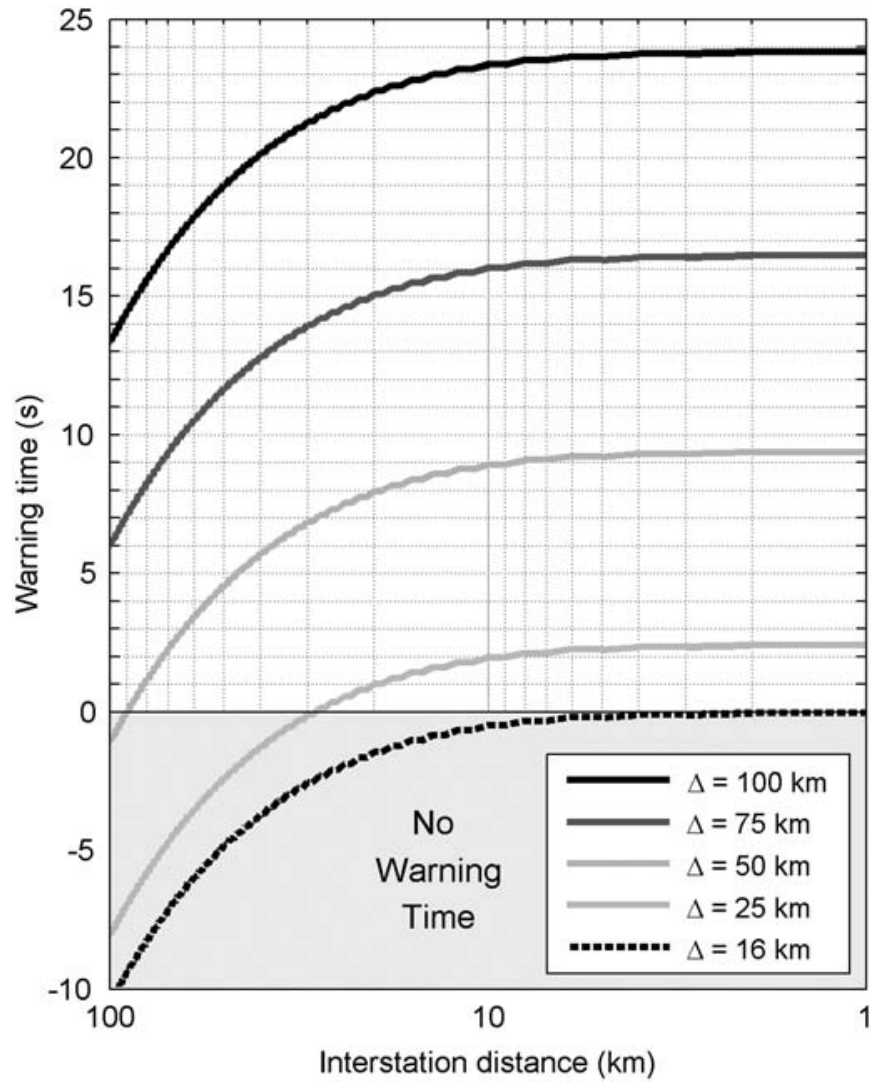

A Figure 6. Variation of warning time at locations 16, 25, 50, 75, and $100 \mathrm{~km}$ from the earthquake epicenter as a function of the interstation distance. Negative warning times indicate a warning is not possible. The earthquake depth is set at $8 \mathrm{~km}, P$-wave arrival is required at four stations, and we assume the assumed system delay is $4 \mathrm{~s}$. Only small improvement in warning time is observed for station densities less than $10 \mathrm{~km}$. The dashed line represents a location $16 \mathrm{~km}$ far away from the epicenter for which no warning time is possible, irrespective of network density.

function of the interstation distance (Fig. 6). For a location $100 \mathrm{~km}$ from the earthquake epicenter, the warning time can range from 13 to $24 \mathrm{~s}$ depending on interstation distances. However, we find the warning time asymptotes toward a constant value for interstation distance less than $10 \mathrm{~km}$. Any location within $16 \mathrm{~km}$ of the epicenter will always be inside the blind zone even if the interstation distance is very small $(<1 \mathrm{~km})$ near the earthquake epicenter (i.e., no warning time can be issued for locations $16 \mathrm{~km}$ from the earthquake epicenter).

We explored the distribution of interstation distances within the CISN. At each of the California stations, we assign an average interstation distance value, which is computed from the average distance to the three closest stations. From these values, we create a contour map of interstation distances using a linear interpolation between stations (Fig. 7a). We find that $\sim 50 \%$ of California has an average interstation distance of $50 \mathrm{~km}$ or more (Fig. 7a, primarily yellow regions), whereas highly populated areas, such as the San Francisco Bay and 

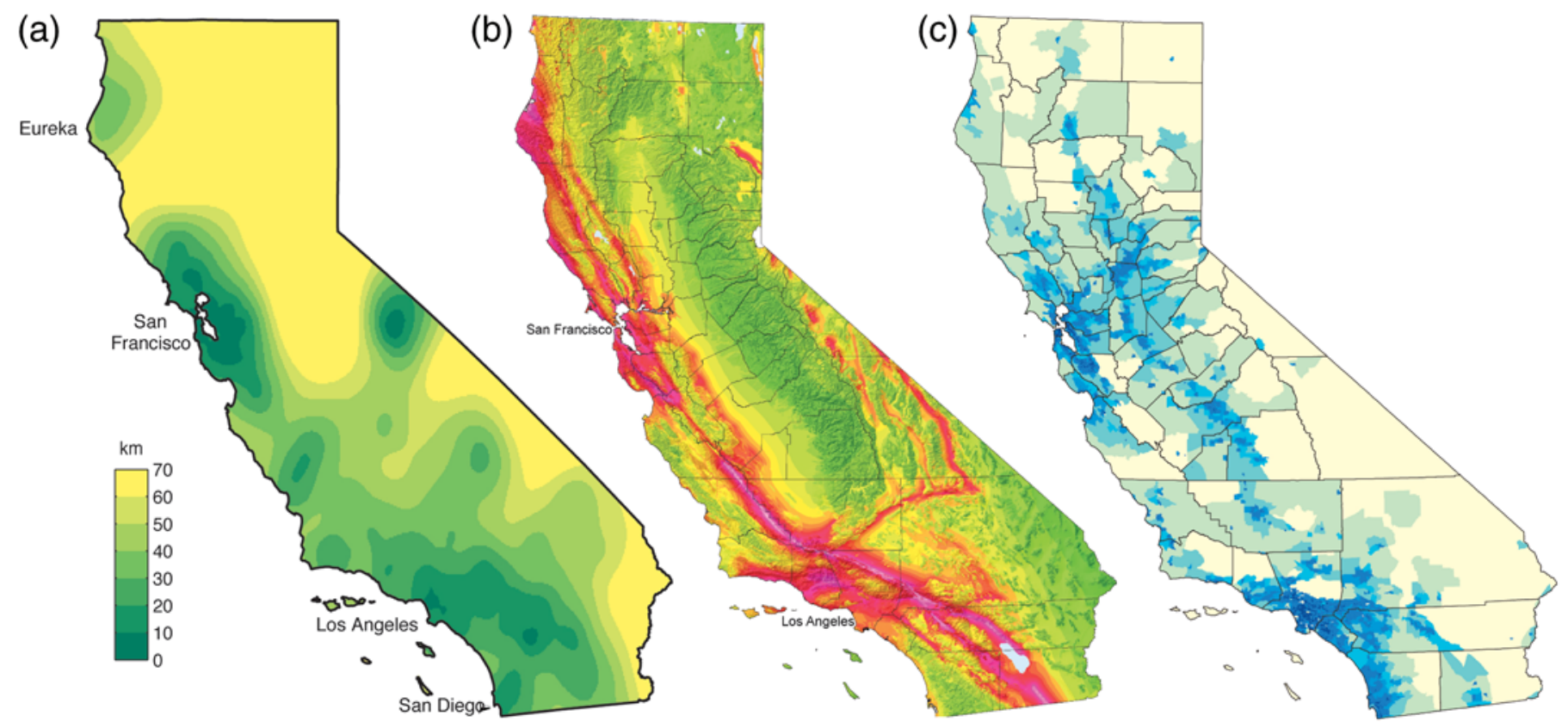

A Figure 7. (a) Seismic-station interstation density map in which yellow colors indicate lower densities. For a given station location, the interstation density is determined by averaging the distance to the nearest three stations. (b) Probabilistic seismic-hazard map (State of California, 2008). (c) Population density of California (U.S. Census Bureau, 2010). For larger resolution images, see the References for the appropriate links.

the Los Angles regions have less than $30 \mathrm{~km}$ spacing (Fig. 7a, green colors).

An EEWS should be devised to be the most robust at issuing alerts in regions identified as having high shaking potential from earthquakes in combination with a large population base from the standpoint of probabilistic seismic hazard. For California, we can examine this using a two-step process. The first is to assess which regions have both a high shaking potential (Fig. 7b) and a large population density (Fig. 7c). The seismic networks have been designed to have higher station densities in the regions of higher population. Qualitatively, regions that have both large populations as well as high likelihood of experiencing strong shaking include: The extended Los Angeles and San Francisco Bay regions, and the southern part of the San Andreas fault (SAF). In the second step, we evaluate if the interstation distances in these identified regions are at or below the $20 \mathrm{~km}$. For the southern part of the central SAF, between San Jose and Los Angeles, we find there are an inadequate number of stations. In this critical part of California, the interstation distance varies from 30 to $50 \mathrm{~km}$. These values are well outside the desired interstation distance of $20 \mathrm{~km}$ or less. Currently, the number of stations covering this portion of the San Andrea Fault is 10. Putting 20 more stations on the two sides of the fault would increase the EEWS accuracy and warning time tremendously for populated cities on Route 99, the main highway between from Sacramento to Bakersfield, as well as increasing warning times for big earthquakes that rupture toward San Francisco or Los Angeles. Another region with sparse station coverage and high-shaking potential is north of the San Francisco Bay area and south of Eureka, where the interstation distance exceeds $60 \mathrm{~km}$. Because of the sparse coverage, earthquakes in the Mendocino Triple Junction (offshore Eureka) are also difficult to detect and to accurately characterize.

We next compare the CISN station density map with the spatial distribution of 407 large California earthquakes $(\mathbf{M} \geq 5)$ that occurred in the years 1900-2012 (Fig. 8). Although there is some correlation between regions of high seismicity and dense station coverage (e.g., in the Los Angeles and Mammoth Lakes regions), we find many regions with minimal correlation, suggesting the station density is likely inadequate for successful EEWS. One region that needs denser station coverage is in the northeastern part of California, and we could consider this zone as being similar to offshore regions in terms of network distribution and its ability to characterize these events. To improve EEWS in this region would require a denser station network. Another problematic region is the Mendocino Triple Junction, where there are less than 10 stations within a similar area covering the Greater Bay area. The paucity of stations in this region can result in large uncertainties in estimates of the location and magnitude of offshore earthquakes, which, in turn, increase uncertainties in EEWS predictions onshore. Other parts of California, such as south of San Jose, Bakersfield, and west of the greater Los Angeles area, also have station distributions that are not optimal for EEWS (i.e., interstation distances exceed $30 \mathrm{~km}$ ).

\section{Comparison of the California and Japan EEWS}

We next compared the station distribution of the Japanese JMA/NIED EEWS with the California CISN ShakeAlert 
(a)

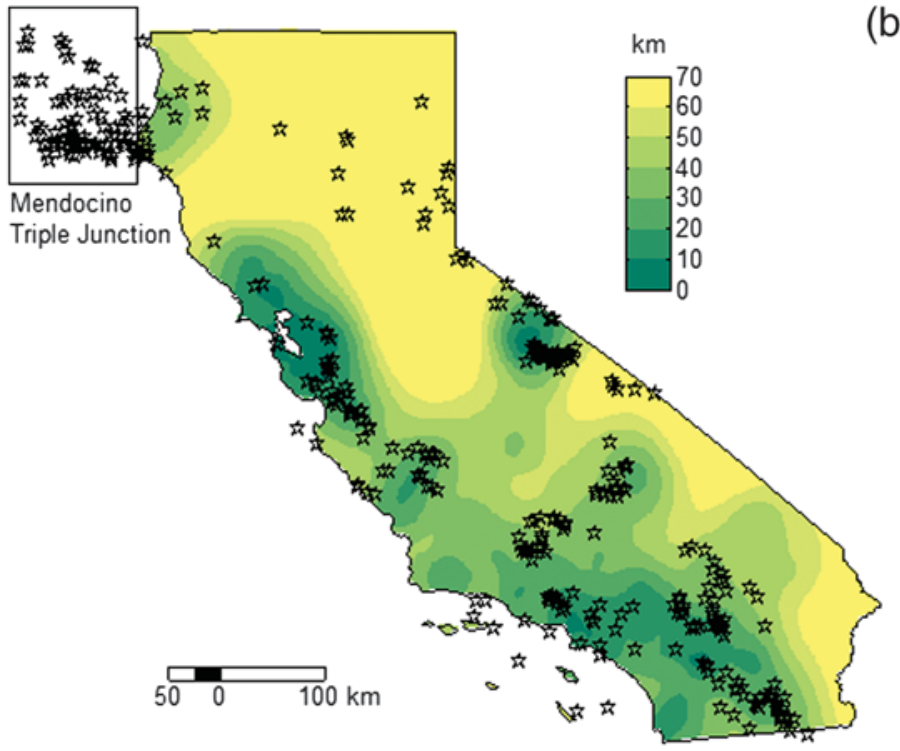

(b)

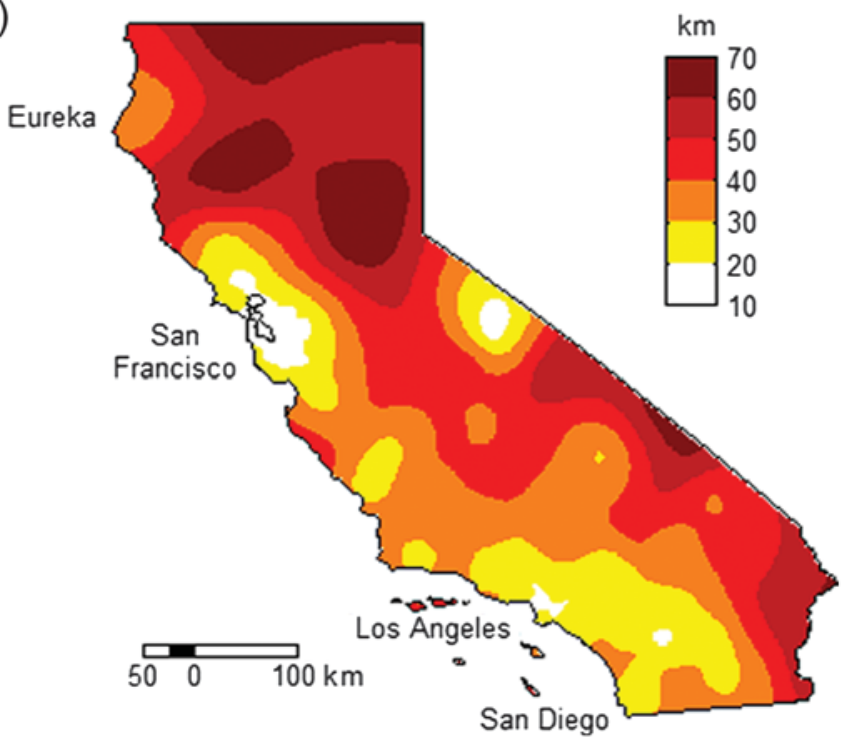

D Figure 8. (a) Epicenters of $407 \mathbf{M}>5$ earthquakes from 1900 to 2012 juxtaposed on the interstation-distance contour map of Figure 7. (b) Map of blind-zone radius for California. Yellow and orange colors correspond to regions with small blind zones and red and dark-red colors correspond to regions with large blind zones.

EEWS, keeping in mind that the Hi-net and JMA networks are comparatively newer than most of the CISN networks, and were in some sense designed with EEWS in mind, whereas the CISN configuration was not. The number of stations (1089) used in the JMA/NIED EEWS is $~ 3$ times higher than the number of stations (377) that contribute to the CISN ShakeAlert EEWS (Table 1), whereas the area of the two regions is similar. The main difference between these two different EEWS configurations is that the interstation distances of California have a very nonuniform distribution (Fig. 7a), whereas the interstation distances of Japan have a very uniform station density (Fig. 9).

Comparing the median interstation distance of stations in the Japan network with that of the California network we find some striking differences. First, histograms of the distributions (Fig. 10) show the Japan JMA/NIED network has a near- normal distribution with a mean of $18.7 \pm 9.1 \mathrm{~km}$, whereas the California CISN ShakeAlert EEWS histogram has a nonnormal distribution with a median of $14.7 \mathrm{~km}$. The CISN distribution is skewed at the small-distance end by very dense network configurations in the San Francisco Bay and Los Angeles areas. Within these networks, there are 107 stations (10\%) of JMA/NIED that have interstation distances less than $10 \mathrm{~km}$ and $123(33 \%)$ stations in California. These 123 stations, although useful for other seismological studies, may contribute little information for the EEWS purposes. However, they do provide a backup to other stations close by in the highly populated regions of downtown San Francisco, Berkeley, San Jose, and some parts of Los Angeles. On the other hand, interstation distances that exceed $30 \mathrm{~km}$ are found at $25 \%$ (94 stations out of 377) and 6\% (68 stations out of 877) for the CISN and JMA/NIED networks, respectively (Fig. 10).

\begin{tabular}{|lcc|}
\hline \multicolumn{2}{|c|}{ Table 1 } & \\
Comparison of the Number of Stations Used in the California and Japan EEWSs & Japan JMA/NIED \\
& California CISN \\
& ShakeAlert EEWS & 34 \\
\hline University California Berkeley Digital Seismic Network, BK & 99 \\
USGS Northern California Seismic Network, NC & 58 \\
USGS National Strong Motion Program, NP & 171 \\
USGS/Caltech Southern California Seismic Network and TriNet, Cl & 15 & 873 \\
University California San Diego Anza Network, AZ & & 216 \\
High Sensitivity Seismograph Network Japan, Hi-Net & 377 & 1089 \\
Japanese Meteorological Agency, JMA & & \\
Total & & \\
\hline
\end{tabular}




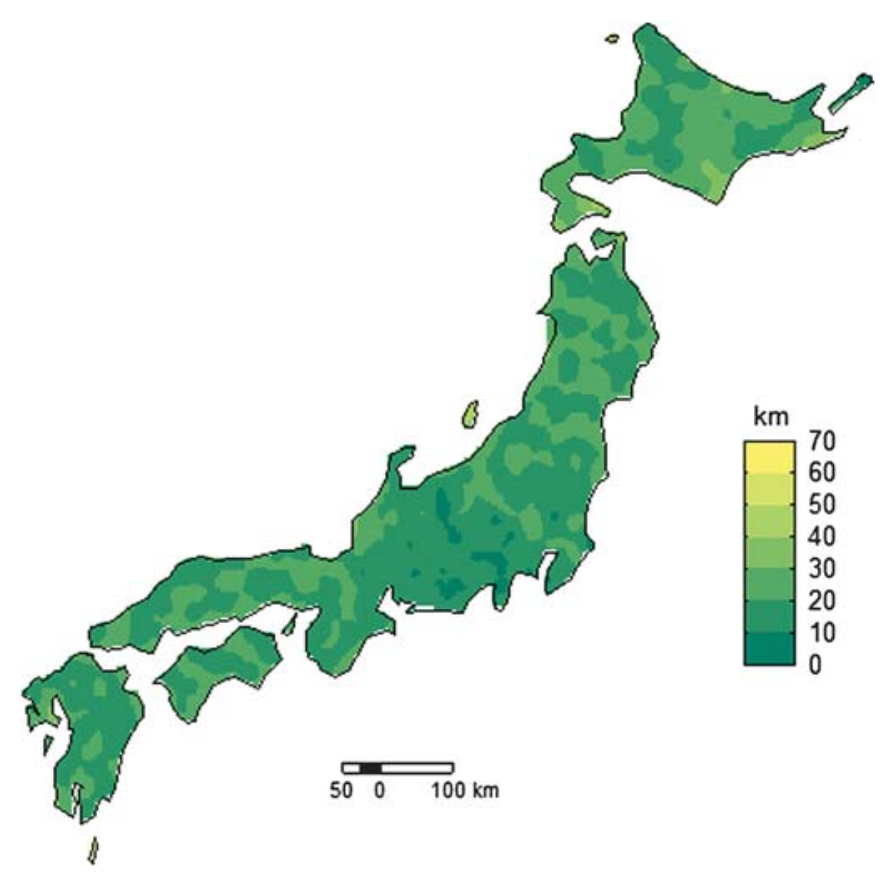

$\Delta$ Figure 9. Station-density map of the Japan JMA/NIED EEWS. The method used to compute this map is identical to that used to generate Figures 7 and 8 . The average station density is between 10 and $30 \mathrm{~km}$ across the whole country.

Assuming the ideal interstation spacing is between 10 and $20 \mathrm{~km}$, only $42 \%$ (160) stations in the CISN ShakeAlert EEWS would be considered well situated, whereas the percentage is double that at $84 \%$ (914 stations) for the JMA/NIED stations.

(a)

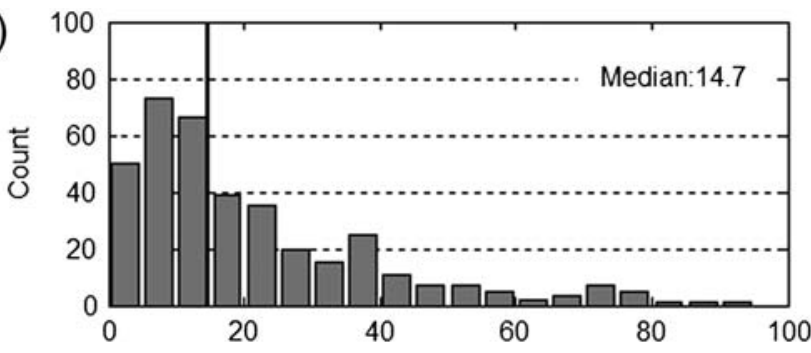

(b)

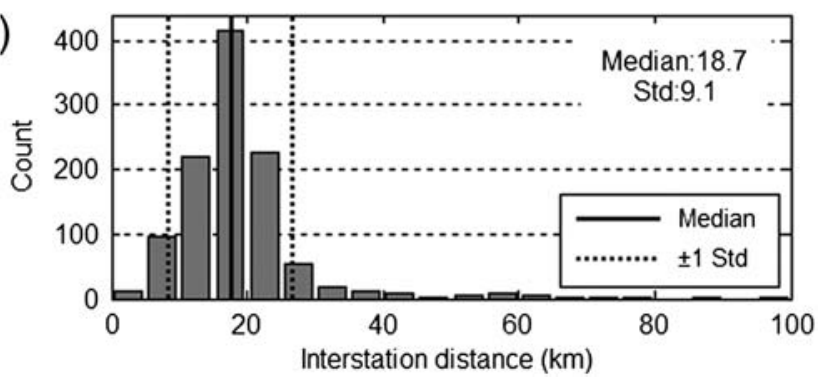

A Figure 10. Histogram of interstation distance determined for each station calculated by averaging the distance to the three closest stations. Results from: (a) the CISN/ShakeAlert/EEW Networks and (b) the combined Hi-net and JMA networks.

\section{DISCUSSION}

Because of the interdependence between warning time and interstation distance, we propose that, in general, we need to have smaller interstation distances surrounding known active faults, particularly within large metropolitan areas. This will increase the warning time for densely populated cities. However, the dense station coverage should also be extended along the hazardous faults adjacent to the metropolitan regions in order to improve warning times for earthquakes that occur adjacent to the cities. For example, San Jose has a very dense station coverage with a mean station spacing of $<10 \mathrm{~km}$ (Fig. 7a). If a large earthquake occurred in San Jose, a $24 \mathrm{~s}$ warning time could be issued to those living $100 \mathrm{~km}$ south of the city because of the dense coverage close to the San Jose epicenter (Fig. 6). Whereas, if the earthquake was $100 \mathrm{~km}$ south of the city where the station density is low (spacing of $30-40 \mathrm{~km}$ ), then a warning time of only $17 \mathrm{~s}$ would be available to San Jose residents.

Several regions in California have inadequate station coverage to support successful EEWS. It has already been identified that the CISN ShakeAlert EEWS is facing problems within some parts of California where station coverage is inadequate or unevenly distributed (Allen et al., 2009). Two areas stand out where there is both high risk of earthquake rupture and very low station density: along the SAF between San Jose and Los Angeles, and to the north of the San Francisco Bay area. Investment in increased station density in these regions would not just decrease the blind zone for earthquakes in those regions, but also will increase available warning time for other populated regions such as Los Angeles and the San Francisco Bay areas.

Improved, that is, reduced, interstation distance could be achieved in a number of ways: (1) upgrading infrastructure at selected existing stations, such as employing new loggers and faster telecommunication devices. There are currently $\sim 2900$ station sites in California, but only $\sim 377$ with equipment suitable for an EEWS. The advantage of upgrading these sites is that the operating costs are already covered; the only cost needed is to upgrade hardware. (2) Integrating Nevada stations into the warning system would help improve the coverage for eastern and particularly northeastern California. (3) Relocating some existing stations. There are more than 100 stations in California with interstation distances less than $10 \mathrm{~km}$ (almost half of them have $<5 \mathrm{~km}$ spacing), relocation of some could make a big difference to warning times in other regions. (4) Employing new stations to fill the gaps between existing stations and known seismic zones.

\section{CONCLUSION AND RECOMMENDATIONS}

Based on quantitative estimates of the current CISN/EEWS infrastructure, we conclude that the blind-zone radius throughout California is highly heterogeneous (Fig. 8b). The minimum blind-zone radius is $\sim 16 \mathrm{~km}$ for typical California earthquakes with $8 \mathrm{~km}$ depth, and when four station detections are required 
by a system with a $4 \mathrm{~s}$ processing/communications delay. Therefore, based on current constraints, there will be no time to issue a warning for any location within $16 \mathrm{~km}$ of a large earthquake. This limit of $16 \mathrm{~km}$ could be decreased if we address technical and algorithm issues, such as reducing the telemetry delay, decision-making time, and so on.

Blind-zone radius increases with larger interstation distance. Throughout most of the greater San Francisco Bay and Los Angeles areas, the blind-zone radius is less than $30 \mathrm{~km}$. These regions would likely get warnings for earthquakes that occur at distances that exceed $20 \mathrm{~km}$. In other regions of California, particularly in northern California where the station spacing is much sparser (e.g., interstation distances of $>70 \mathrm{~km}$ ), the blind-zone radius is much larger. Our results show that successful warnings could only be issued for earthquakes at distances $50 \mathrm{~km}$ or more away from the earthquake location.

Three key factors effect the optimization of interstation distance and station distribution: (1) budget, (2) population/ property distribution, and (3) probability of expected earthquakes (past seismicity/known faults). The theoretical work presented in this paper suggests targeting a $\sim 10 \mathrm{~km}$ station spacing on known faults is ideal, and this $10 \mathrm{~km}$ spacing is most critical in urban regions that are in close proximity to known faults. There are diminishing benefits to smaller station spacing than this. In urban areas well away from known faults, larger interstation spacing becomes more acceptable as an extra second of delay is not too critical as the urban centers are some distance from the epicenter. The target spacing for regions with hazardous faults that are away from population centers could be $\sim 20 \mathrm{~km}$. Furthermore, for deep earthquakes, such as the 2001 Nisqually earthquake (with $52 \mathrm{~km}$ depth) in Washington, there is no benefit if interstation distance is less than $50 \mathrm{~km}$ (though shallow earthquakes may also be a threat in these regions).

Once dense station distributions $(10-20 \mathrm{~km})$ have been achieved, the increase to the warning time available by issuing alerts with fewer stations detection, that is, issuing an alert when there are fewer than four stations detecting a $P$ wave, is significantly diminished. The benefits of algorithms that use few station detections, such as single-station detection, are most apparent in regions with very low station density, such as northernmost and eastern California.

The current distribution of stations in the California CISN was not designed for EEWS purposes. The capabilities of an EEWS are primarily determined by station distribution. The approach taken to building the networks for the Japanese EEWS was to have an even station distribution of $18.7 \mathrm{~km}$ across the country. In California, the distribution of station is currently not adequate for EEWS. However, in our budgetlimited reality, optimum performance is also not achieved by even station distribution. Stations should be (1) densest $(\sim 10 \mathrm{~km})$ in the urban areas that are above hazardous faults, (2) fairly dense $(\sim 20 \mathrm{~km})$ along hazardous faults away from urban centers, and (3) least dense in other regions. Based on the current distribution of stations and hazards in California, the areas between San Jose and northern Los Angeles, and between Eureka and the San Francisco Bay area need immediate attention if we would like to enhance EEWS in California. $\$$

\section{ACKNOWLEDGMENTS}

This work is funded by USGS/NEHRP award G12AC20348, and by the Gordon and Betty Moore Foundation through Grant GBMF3024 to UC Berkeley. We would like to thank Muharrem Aktas and John Clinton for their review and their valuable comments. We thank Mitsuyuki Hoshiba for providing information on JMA/NIED EEW stations. We are also grateful to Deborah Kilb for assisting with editing the manuscript.

\section{REFERENCES}

Aktas, M., H. S. Kuyuk, and H. Aslan (2010). Traffic Management for Bosphorus Suspended Bridge, Istanbul information based on earthquake real-time information, in 14th European Conference on Earthquake Engineering, Ohrid, Republic of Macedonia, 30 August-3 September.

Allen, R. M., H. Brown, M. Hellweg, O. Khainovski, P. Lombard, and D. Neuhauser (2009). Real-time earthquake detection and hazard assessment by ElarmS across California, Geophys. Res. Lett. 36, L00B08, doi: 10.1029/2008GL036766.

Boese, M., R. Allen, H. Brown, G. Cua, M. Fischer, E. Hauksson, T. Heaton, M. Hellweg, M. Liukis, D. Neuhauser, P. Maechling, and CISN EEW Group (2013). CISN ShakeAlert: An Earthquake Early Warning Demonstration System for California, in Early Warning for Geological Disasters-Scientific Methods and Current Practice Earthquake Early Warning Systems, F. Wenzel and J. Zschau (Editors), Springer, Berlin, Heidelberg, New York, ISBN: 978-3-642-12232-3 (http://www.springer.com/earth+sciences+and +geography/geophysics/book/978-3-642-12232-3, last accessed September 2013).

Brown, H. M., R. M. Allen, M. Hellweg, O. Khainovski, D. Neuhauser, and A. Souf (2011). Development of the ElarmS methodology for earthquake early warning: Realtime application in California and offline testing in Japan, Soil Dynam. Earthq. Eng. 31, 188-200, doi: 10.1016/j.soildyn.2010.03.008.

Hauksson, E., and P. Shearer (2005). Southern California hypocenter relocation with waveform cross-correlation, part 1: Results using the double-difference method, Bull. Seismol. Soc. Am. 95, no. 3, 896-903, doi: 10.1785/0120040167.

Hoshiba, M., K. Iwakiri, N. Hayashimoto, T. Shimoyama, K. Hirano, Y. Yamada, Y. Ishigaki, and H. Kikuta (2011). Outline of the 2011 off the Pacific Coast of Tohoku earthquake $\left(M_{\mathrm{w}}\right.$ 9.0): Earthquake Early Warning and observed seismic intensity, Earth Planets Space 63, 547-551.

Japanese Meteorological Agency (2012). Survey on utilization of Earthquake Early Warning System, Japanese Meteorological Agency Reports (in Japanese), (http://www.jma.go.jp/jma/press/1203/22c/ 23manzokudo_data.pdf, last accessed August 2013).

Kilb, D., and J. Gomberg (1999). The initial subevent of the 1994 Northridge, California, earthquake: Is earthquake size predictable? J. Seismol. 3, 409-420.

Kuyuk, H. S. (2010). Available warning time for emergency response in Sakarya City, Turkey against possible Marmara earthquake, in 9th International Congress on Advances in Civil Engineering, Trabzon, Turkey, 27-30 September.

Kuyuk, H. S., H. Brown, R. M. Allen, I. Henson, M. Hellweg, and D. Neuhauser (2013). Designing a network-based earthquake early 
warning system for California: ElarmS-2, Bull. Seismol. Soc. Am. (in press).

Kuyuk, H. S., M. Motosaka, and M. Homma (2008). Available warning time for emergency response in Sendai City, Japan against Miyagi-oki subduction earthquakes based on national and regional earthquake early warning system, in 14th World Conference on Earthquake Engineering, Beijing, China.

Nakamura, Y. (1988). On the urgent earthquake detection and alarm system (UrEDAS), in Proc. of 9th World Conference on Earthquake Engineering, Tokyo-Kyoto, Japan.

State of California, Department of Conservation (2008). Regional Geologic Hazards and Mapping Program, Probabilistic Seismic Hazard Map (http://www.consrv.ca.gov/cgs/rghm/psha/Pages/Index.aspx, last accessed March 2013).

U.S. Census Bureau, U.S. Department of Commerce, Economics, and Statistics Administration(2010) (http://www2.census.gov/geo/ maps/dc10_thematic/2010_Profile/2010_Profile_Map_California.pdf, last accessed March 2013).

\section{H. Serdar Kuyuk ${ }^{1}$ \\ Department of Civil Engineering Sakarya University \\ Sakarya, Turkey, 54100 \\ serdarkuyuk@gmail.com}

Richard M. Allen

Seismological Laboratory

University of California Berkeley, California U.S.A.

\footnotetext{
1 Also at Seismological Laboratory, University of California, 209 McCone Hall, Berkeley, California 94720 U.S.A.;
}

skuyuk@seismo.berkeley.edu. 